\title{
Understanding the Performance of a Microfluidic Electrolysis Cell for Routine Organic Electrosynthesis
}

\author{
Robert A. Green*, Richard C. D. Brown and Derek Pletcher \\ Chemistry, University of Southampton, Southampton SO17 1 BJ, UK
}

\begin{abstract}
In order for microflow electrolysis cells to make their full contribution to routine, laboratory organic synthesis, they must be capable of carrying out reactions with good selectivity and high conversion at a high rate of conversion. In addition to appropriate choice of the electrolysis medium and control of the overall cell chemistry, both the design of the electrolysis cell (including materials of construction) and the correct selection of the cell current and flow rate of the solution are critical in determining performance. The conclusions are tested using the methoxylation of $\mathrm{N}$-formylpyrrolidine as the test reaction in a microflow electrolysis cell with a single, long, patterned flow channel.
\end{abstract}

Keywords: electrochemistry, flow chemistry, electrolysis cell, oxidation, methoxylation reactions.

* Author for correspondence: E-mail address: rag1c10@soton.ac.uk 


\section{Introduction}

With their ability to deliver improved selectivities, higher yields and faster conversions, microflow reactors now have an established role in the synthetic organic laboratory [1]. A number of flow electrolysis cells designed to contribute to this chemistry have been described [2]; while some interesting reactions have been reported, most do not fit well with other microflow equipment or meet all the performance requirements, particularly ease of operation by non-specialists, high rate of product formation, high conversion and high selectivity.
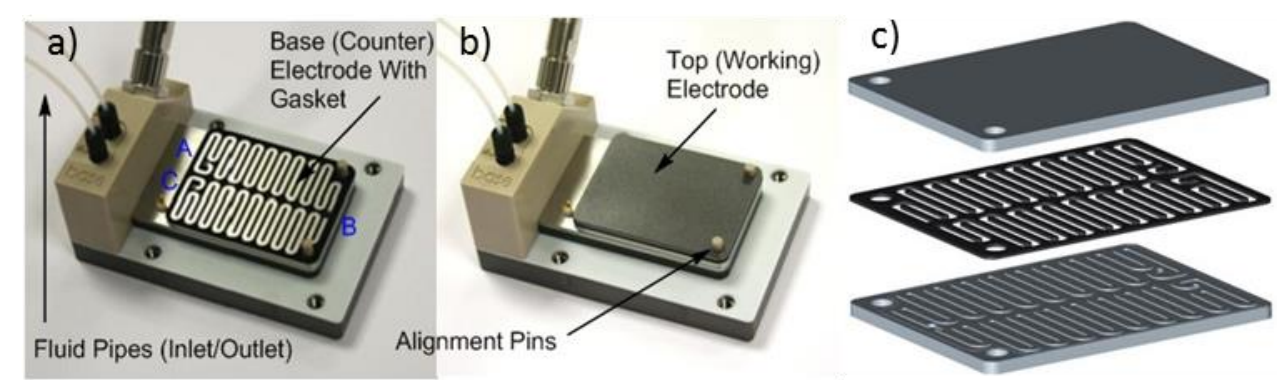

Figure 1 Photographs of the microflow cell and components. (a) Electrolysis cell showing recessed electrode and gasket. (b) Electrolysis cell with top electrode. (c) Graphic showing arrangement of recessed electrode, gasket and top electrode.

Gaining the full benefit of microflow electrolysis cells for organic electrosynthesis, however, requires the understanding of both the organic chemistry and the characteristics of the electrolysis cell. This paper sets out the factors that should be considered in seeking good performance from such microflow electrolysis cells. The conclusions are tested using an electrolysis microflow cell based on a single, long, tortuous patterned flow channel [3], see figure 1, readily integrated into microflow equipment and using the methoxylation of $\mathrm{N}$ formylpyrrolidine as the test reaction. The anode and cathode reactions, along with the overall transformation are shown in scheme 1 . The reaction of protons with the methoxide formed at the cathode ensures that the medium remains neutral through the channel. 
Anode:

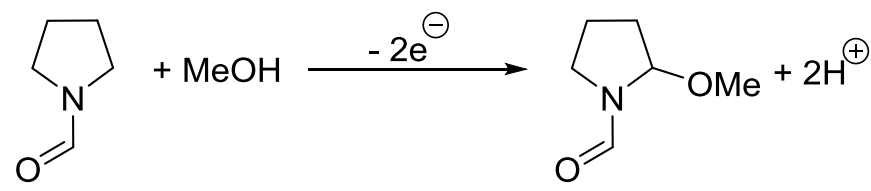

Cathode:

$2 \mathrm{MeOH} \stackrel{+2 \mathrm{e}^{\ominus}}{\longrightarrow} 2 \mathrm{MeO}^{\ominus}+\mathrm{H}_{2}$

Electrolyte:

$2 \mathrm{MeO}^{\ominus}+2 \mathrm{H}^{\oplus} \longrightarrow 2 \mathrm{MeOH}$

Overall:

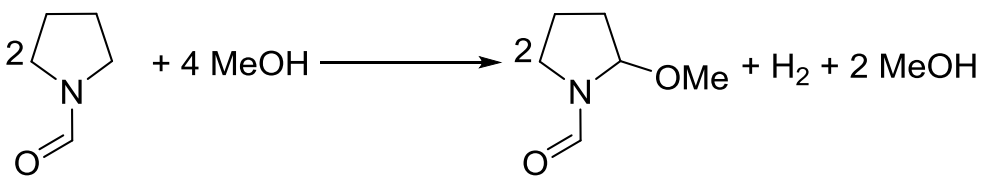

Scheme 1 Anode and cathode reactions occurring in the flow electrolysis cell.

A microflow electrolysis cell with a similar design has recently been employed for the oxidation of substituted toluenes [4] and for the investigation of the metabolites from the oxidation of a number of drugs [5] although it is clear from the performance reported that the cell was operated away from the optimum conditions.

\subsection{Understanding Microflow Electrolysis Cells}

In general, the microflow cells in the literature are undivided and operated with a constant current. The former requires the influence of the chemical changes at both working and counter electrodes on the cell performance to be considered. Clearly, a clean conversion at the working electrode is essential and this is largely determined by the chemistry of the reaction intermediates formed at the working electrode and the electrolysis medium; the susceptibility of the product to further oxidation/reduction at the working electrode will be important to cell performance. In addition, however, the reactant and product must not be oxidised/reduced at the counter electrode and the chemical change at the counter electrode must not influence adversely the chemistry at the working electrode. Certainly, it is the overall chemical change in the cell that will determine the cell performance. A favourable strategy is a paired electrosynthesis where desirable transformations are carried out at both electrodes [6,7]. A more generally applicable approach (used in the methoxylation of $N$ formylpyrrolidine, (see scheme 1 above) is to use the counter electrode to maintain a constant $\mathrm{pH}$ along the channel although this will normally involve gas evolution and the resulting gas 
bubbles will have an influence on the performance of a cell with a channel of small dimensions.

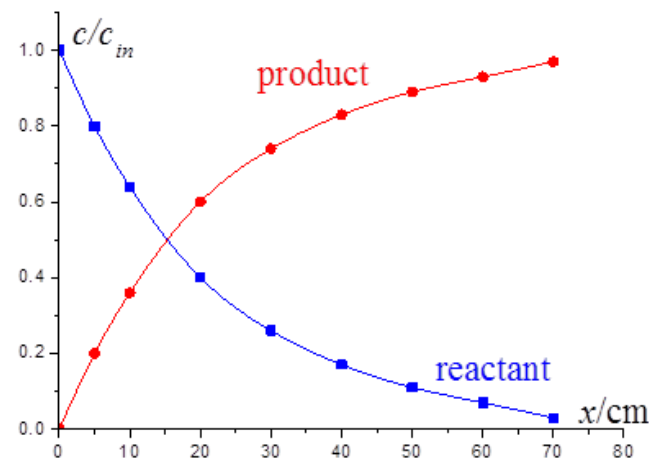

a)

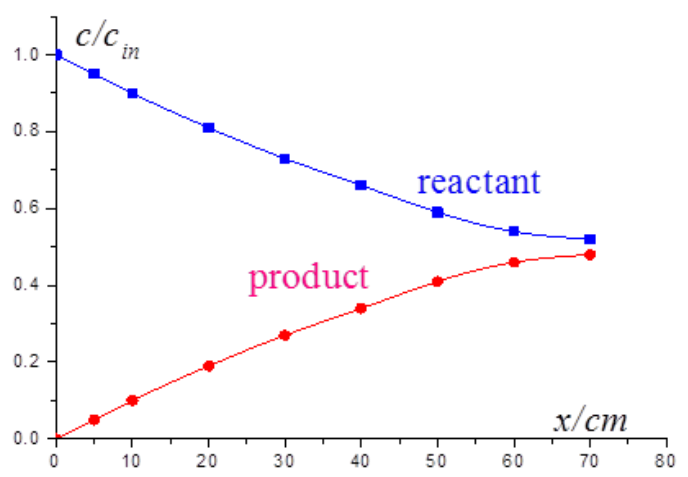

b)

Figure 2 Conversion of reactant into product as a function of distance along the channel, $\mathrm{x}$. Concentrations calculated using equations (1) and (5) and the characteristics of the microflow cell used in this work. Volumetric flow rate (A) $0.1 \mathrm{~cm}^{3} \min ^{-1}$ (B) $3 \mathrm{~cm}^{3} \mathrm{~min}^{-1}$.

In the microflow electrolysis cell, the goal will be to approach full conversion of reactant to product by the exit to the cell. The variation of reactant and product concentrations along the channel will have the general forms shown in figure 2. The concentration of reactant will drop and the product will build up along the channel. If the product is susceptible to further electrode reactions, such chemistry will be most likely towards the exit to the channel. The highest conversion will be found when the electrode reaction is mass transport controlled. In these conditions but in the absence of gas bubble formation within the microchannel, the electrolysis cell may be modelled as a single pass, plug flow reactor as discussed in standard texts of electrochemistry and electrochemical engineering [8]. For a single pass, plug flow electrolysis cell, the fractional conversion, $X$, is given by

$$
X=1-\frac{c_{\text {out }}}{c_{\text {in }}}=1-\exp \left[-\frac{k_{m} w L}{Q_{V}}\right]
$$

where $c_{\text {in }}$ and $\left.c_{\text {out }}(\mathrm{mol} \mathrm{cm})^{-3}\right)$ are the concentrations of the electroactive species at the beginning and end of the cell channel $(\mathrm{x}=0$ and $\mathrm{x}=\mathrm{L})$ respectively, $k_{m}\left(\mathrm{~cm} \mathrm{~s}^{-1}\right)$ the space averaged mass transfer coefficient (a function of the volumetric flow rate of the reactant solution, $\left.Q_{V}\left(\mathrm{~cm}^{3} \mathrm{~s}^{-1}\right)\right), w(\mathrm{~cm})$ the width of the channel and $L(\mathrm{~cm})$ the length of the channel. The decay in reactant concentration along the channel can be seen to be exponential. Figure 2 
shows plots of normalised reactant and product concentrations as a function of distance along the channel, $x$, for the microflow cell used in this work and for two flow rates of 0.1 and 3.0 $\mathrm{cm}^{3} \mathrm{~min}^{-1}$. It can be seen that the theory predicts a high conversion for the slower flow rate. In general, for a high fractional conversion, the mass transport regime in the channel and the length of the channel must be sufficient for the flow rate employed. Hence with a flow rate of $3.0 \mathrm{~cm}^{3} \mathrm{~min}^{-1}$ the conversion can be seen to be much lower. While to some extent the fraction of conversion also depends on the channel width, $w$, increasing $w$ also has the effect of lowering the linear flow rate of solution through the channel (at fixed $Q_{V}$ ) and hence the mass transfer coefficient, $k_{m}$. Overall, it is clear that the conversion depends strongly on the design of the microflow electrolysis cell and achieving a high conversion in a single pass is always a major challenge, certainly only possible with an extended channel length if the flow rate is to approach the $\mathrm{cm}^{3} \mathrm{~min}^{-1}$ flow rates advantageous in microflow synthesis. On the other hand, it should be noted that the fractional conversion should be independent of the concentration of reactant fed to the cell.

The cell current, $I_{o p t}$, (A) required to achieve the fractional conversion, $X$, demanded by equation (1) is given by

$$
I_{\text {cell }}=I_{o p t}=n F Q_{V} c_{i n} X
$$

where $n$ is the number of electrons required for the chemical conversion at the working electrode, $F\left(\mathrm{~A} \mathrm{~s} \mathrm{~mol}^{-1}\right)$ the Faraday constant, $Q_{V}\left(\mathrm{~cm}^{3} \mathrm{~s}^{-1}\right)$ the volumetric flow rate of the reactant solution and $\left.c_{\text {in }}(\mathrm{mol} \mathrm{cm})^{-3}\right)$ the concentration of the reactant at the inlet to the cell. This optimum cell current is not dependent on the cell design and it is essentially a statement of Faraday's laws - the number of moles of chemical change is proportional to the charge passed. The cell design only determines whether the conversion is, in fact, possible.

It should also be stressed that in any conditions, $I_{\text {cell }}$ is always the integral of the variable local currents along the channel. As the conversion of reactant to product occurs along the channel, the reactant concentration decreases and, with it, the local current density must decrease along the channel. For example, for a $95 \%$ conversion, the current density for the desired reaction at the exit to the channel will be only $5 \%$ of the current density at the entry to the channel. Indeed, the variation of the local current with length of the channel, $x$ (cm), will follow the $\mathrm{c}$ vs $\mathrm{x}$ plots of figure 2; the current decreases exponentially with the distance along the channel. 
Failure to operate with $I_{c e l l}=I_{o p t}$ will, however, inevitably lead to a loss in the performance of the cell. If $I_{\text {cell }}<I_{o p t}$, a full conversion cannot be achieved. If $I_{\text {cell }}>I_{o p t}$, another, competing reaction will be occurring at the working electrode (over oxidation/reduction of the reactant, decomposition of the solvent/electrolyte etc), probably leading to a lower selectivity and complexity in the isolation of pure product. Even using the optimum cell current does not alone ensure high selectivity and conversion. This is only possible if the cell design is such that the fractional conversion, $X$, can actually be achieved and hence there is the appropriate distribution of the local currents along the channel. If this is not the case, even when $I_{c e l l}=I_{\text {opt }}$, as well as lower conversion, competing reactions will occur and there will be a loss of selectivity. Practically, the correct distribution of local currents along the channel and the ability of the cell to achieve the desired conversion can only be inferred from the experimental determination of the fractional conversion and comparison with the theoretical value.

The optimum cell current is proportional to both the inlet reactant concentration and the flow rate. When using these parameters to increase the rate of product formation, it should also be recognised that the current, $I_{\text {opt }}$, may not be achievable in the laboratory. The maximum cell current may in practice be determined by (i) the instrumentation used to control the current since this will have a maximum current output (ii) the volume of gas formed at the counter electrode (proportional to the cell current) might degrade the cell performance (iii) the temperature rise due to the voltage drop across the interelectrode gap (proportional to $I_{\text {cell }}^{2} R_{\text {cell }}$ ) will increase and may become uncontrollable.

Overall, the conclusion is that good cell performance is dependent on achieving the correct current distribution over the length of the channel and this in turn is a function of both the cell design and the cell current (see equations (1) and (2)). It is helpful to consider each of the important performance criteria in turn. Scialdone et al. [9] have addressed the influence of cell design and operating conditions on the performance of microflow electrolysis cells, but stressed only 'conversion' since they were interested in the removal of organic contaminants from effluents.

\subsubsection{Charge efficiency}

In laboratory synthesis, the importance of charge efficiency (alternatively called current efficiency) is largely its influence on selectivity. Charge efficiency is defined by 


$$
\text { charge efficiency }=\frac{q_{\text {theory }}}{q}=\frac{c_{\text {in } V n F X}}{q}
$$

Here, q (C, ie A s) is the charge passed, $q_{\text {theory }}$ is the charge estimated using Faraday's laws for the fractional conversion $X$, and $V\left(\mathrm{~cm}^{3}\right)$ the volume of reactant solution to be converted. When the microflow cell, is operated at the optimum cell current, this optimum charge is given by

$$
q_{o p t}=\frac{I_{o p t} V}{Q_{V}}
$$

Passing less than this charge will inevitably lead to a lower conversion while passage of a greater charge will lead to the occurrence of a competing electrode reaction (over oxidation/reduction of the reactant, decomposition of the solvent/electrolyte etc), probably leading to a lower selectivity and complexity in the isolation of pure product. The full benefit of using $q_{\text {opt }}$ and $I_{\text {opt }}$, will, however only be seen if the lessons of equation (1) are also learnt; the mass transfer coefficient and length of the channel must both be large enough to achieve the desired conversion at the flow rate employed. A charge efficiency approaching one therefore requires the correct selection of cell current, $I_{\text {cell }}$, and flow rate, $Q_{V}$, as well as cell design (hence, $k_{m}$ and $L$ ).

\subsubsection{Selectivity}

The selectivity of the conversion will first depend on the choice of the electrolysis medium; a selectivity approaching $100 \%$ will result only if the intermediate generated at the working electrode reacts through a single pathway to form the desired product. In addition, it is necessary that the reactant and product are inactive at the counter electrode and that the cell current does not exceed $I_{\text {opt }}$ when over oxidation/reduction and solvent/electrolyte decomposition are likely to lead to byproducts. Operating with a cell current below $I_{\text {opt }}$ will probably not adversely affect the selectivity but it will lead to a lower conversion and a lower rate of product formation. As with the charge efficiency, a high selectivity is dependent on both the cell current, flow rate and cell design.

\subsubsection{Conversion}

A high conversion maximises the use of the reactant and generally eases the separation of reactant and product after the electrolysis. The main parameters influencing the conversion are the channel length, $L$, and the flow rate of the solution, $Q_{V}$, see equation (1). 
The conversion will increase as the channel is lengthened and the flow rate is reduced. Several cells in the literature with short channel lengths give good selectivity for interesting chemistry but in order to give a high conversion it is necessary to operate with a very low flow rate and, consequently, a low rate of product formation [2a-c].

Conversion is also dependent on the passage of sufficient charge for the reaction to occur. The cell current will also need to be at least $I_{\text {opt }}$ for the desired conversion, see equations (2). This current demand will increase with the concentration of the reactant, $c_{i n}$, and the flow rate of the solution, $Q_{\mathrm{v}}$, and, as noted above, the cell current demanded may not be achievable in practice because of instrumental limitations, the volume of gas evolved at the counter electrode or failure to cool the cell sufficiently. The maximum sustainable cell current must be determined experimentally.

\subsubsection{Rate of Product Formation}

If the microflow electrolysis cell is to be used for routine synthesis in the laboratory, it is essential that it manufactures the quantity of product required (for a test programme, the next stage in the synthesis, etc.) and a target of several grams per hour is desirable. The amount of product formed will be proportional to the solution flow rate and the concentration of reactant, provided the selectivity and conversion are maintained. The full benefit, however, requires operation of the cell with a current close to $I_{\text {opt }}$ and this will increase with both flow rate and concentration placing increasing demands on the control instrumentation, gas handling and cooling in the cell. The rate of product formation is readily calculated from the inlet reactant concentration, fractional conversion and flow rate.

It should be noted that it may not be possible to define experimental conditions where the optimum charge efficiency, selectivity, conversion and rate of product formation are all obtained and then the electrolysis conditions will depend on the objectives of the synthesis.

In this paper, the electrolyses were carried out in a microflow cell with a single, convoluted channel with pathlength $70 \mathrm{~cm}$, width $0.15 \mathrm{~cm}$ and interelectrode gap $0.02 \mathrm{~cm}$. This gives a total electrode area of $10.5 \mathrm{~cm}^{2}$ and a channel volume of $0.21 \mathrm{~cm}^{3}$ [3]. In this cell, the space averaged mass transfer coefficient in the absence of gas bubble formation can be estimated from the equation

$$
\log k_{m}=-1.64+0.63 \log Q_{V}
$$


over the flow rate range $0.003-0.08 \mathrm{~cm}^{3} \mathrm{~s}^{-1}\left(0.1-4.8 \mathrm{~cm}^{3} \mathrm{~min}^{-1}\right)$ and the units of $Q_{V}$ are $\mathrm{cm}^{3} \mathrm{~s}^{-1}$ and $k_{m}$ are $\mathrm{cm} \mathrm{s}^{-1}$. This equation is taken from the data in figure 2 of reference [3]. Equations (1), (2) and (5) were then used to estimate the performance of the cell for the methoxylation of $N$-formylpyrrolidine and some predictions are reported in table 1 . It can be seen that that the predictions arising are (a) the fractional conversion drops from 0.98 with a flow rate of $0.1 \mathrm{~cm}^{3} \mathrm{~min}^{-1}$ to 0.51 with a flow rate of $3 \mathrm{~cm}^{3} \mathrm{~min}^{-1}$ (b) the current demand rises to $1 \mathrm{~A}$ and beyond and (c) accepting a reduced conversion, it is possible to form several grams per hour.

Table 1 Calculated microflow cell performance for the methoxylation of $\mathrm{N}$-formylpyrrolidine in typical electrolysis conditions.

\begin{tabular}{|c|c|c|c|c|c|c|}
\hline \multicolumn{2}{|c|}{ electrolysis conditions } & \multirow{2}{*}{$\begin{array}{c}\text { I } \\
\text { fractional }\end{array}$} & \multicolumn{2}{c|}{$\begin{array}{c}\text { Rate of product } \\
\text { formation/g hour }\end{array}$} \\
\cline { 5 - 7 } $\begin{array}{c}Q_{V} / \\
\mathrm{cm}^{3} \mathrm{~min}^{-1}\end{array}$ & $\begin{array}{c}\mathrm{c}_{\text {in }} / \\
\mathrm{mol} \mathrm{dm}^{-3}\end{array}$ & $\begin{array}{c}\text { conversion } \\
\text { a }\end{array}$ & $\mathrm{a}$ & $\mathrm{b}$ & $\mathrm{a}$ & $\mathrm{b}$ \\
\hline 0.1 & 0.10 & 0.98 & 0.034 & 0.035 & 0.08 & 0.08 \\
\hline 0.1 & 0.75 & 0.98 & 0.255 & 0.260 & 0.58 & 0.59 \\
\hline 0.5 & 0.10 & 0.82 & 0.082 & 0.100 & 0.19 & 0.23 \\
\hline 0.5 & 0.75 & 0.82 & 0.615 & 0.750 & 1.42 & 1.74 \\
\hline 1.0 & 0.10 & 0.63 & 0.210 & 0.330 & 0.49 & 0.77 \\
\hline 1.0 & 0.75 & 0.63 & 1.57 & 2.50 & 3.63 & 5.80 \\
\hline 3.0 & 0.10 & 0.51 & 0.51 & 1.00 & 1.21 & 2.31 \\
\hline 3.0 & 0.75 & 0.51 & 3.85 & 7.50 & 9.1 & 17.4 \\
\hline
\end{tabular}

a. $\quad$ assuming single pass plug flow (equations (1) and (2) apply).

b. assuming full conversion of reactant to product in a single pass.

While the simple model, assuming plug flow for the microflow cell, facilitates an understanding of how the cell should be used in synthesis, it cannot be expected to predict performance quantitatively since it ignores the gas evolution from the counter electrode (and the gas is clearly observed in the solution exiting the cell). Small gas bubbles in the flow channel will act as turbulence promoters and the gas volume will also increase the linear flow rate of the solution along the channel and both effects will enhance the value of the mass transfer coefficient, $k_{m}$, thereby improving the cell performance. Even if the bubbles coalesce, the larger gas bubbles will still lead to an increase in the linear flow rate. Of course, if the gas blocks off large areas of electrode a negative impact could occur. It is important to recognise the scale of gas evolution; for example, with a cell current of $1 \mathrm{~A}, \sim 7 \mathrm{~cm}^{3} \mathrm{~min}^{-1}$ of $\mathrm{H}_{2}$ gas is 
evolved (at atmospheric pressure) and this compares with solution flow rates of $0.1-4 \mathrm{~cm}^{3}$ $\min ^{-1}$ ! For this reason, in table 1 , we also report the cell current demand and product formation rates if it is assumed that full conversion can be achieved in the electrolysis conditions (calculated using equation (2) with $X=1$. Of course this increases substantially both the cell current demand and the product formation rates and may also adversely affect the selectivity of the reaction.

In reality, it is clearly necessary to determine the cell performance experimentally.

\section{Results}

\subsection{Influence of the Volumetric Flow Rate}

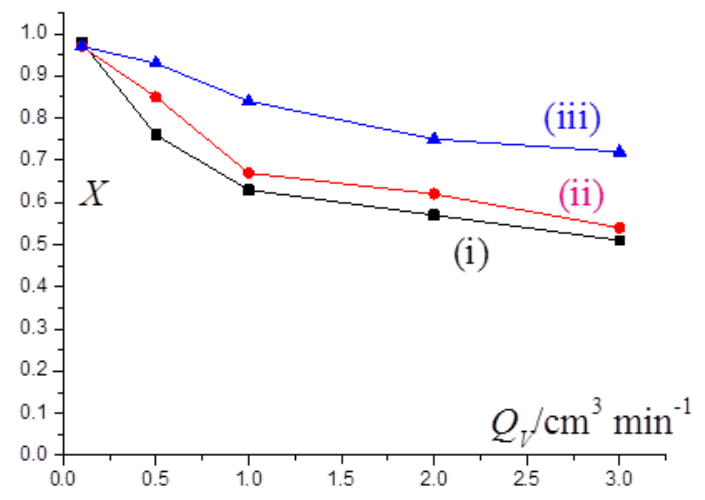

Figure 3 Fractional conversion as a function of the volumetric flow rate (i) calculated using equations (1) and (5) with the characteristics of the experimental microflow cell. (ii) Experimental values using the cell currents calculated from equation (2). (iii) Experimental values using the cell currents for full conversion in a single pass. Inlet concentration of $\mathrm{N}$ formylpyrrolidine, $\mathrm{c}_{\text {in }}=0.2 \mathrm{M}$.

Two sets of electrolyses were carried out to investigate the influence of the volumetric flow rate on conversion. In each experiment the cell was fed with $5.0 \mathrm{~cm}^{3}$ of a solution containing $0.05 \mathrm{M} \mathrm{Bu}_{4} \mathrm{NBF}_{4}+0.2 \mathrm{M} \mathrm{N}$-formylpyrrolidine in methanol. In the first, set the cell currents were those calculated with equation (2) for the conversions predicted using equations (1) and (5). The fractional conversions as a function of volumetric flow rate are reported in figure 3 , curve (ii). Also shown as curve (i) are the fractional conversions calculated using equations (1) and (5). It can be seen that there is good agreement between theory and experiment in these conditions. It can be concluded that in these conditions 
- Plug flow is a good model for the flow conditions in the convoluted microflow channel in these conditions. With these cell currents, the gas evolved at the counter electrode is not significantly changing the flow regime.

- The oxidation of $N$-formylpyrrolidine is mass transfer controlled employing this cell current.

- The concentrations of reactant and products along the channel will follow the plots of figure 2 .

- The charge efficiencies for the conversions are close to $100 \%$.

- However, the fractional conversion is strongly influenced by flow rate dropping by a factor of two as the flow rate is increased from 0.1 to $3 \mathrm{~cm}^{3} \mathrm{~min}^{-1}$.

In order to test whether the fractional conversion could be improved, the cell currents were increased to the values required to have the charge input for full conversion in a single pass (calculated with equation (2) with $X=1$ ) and the fractional conversions are reported in figure 3, curve (iii). It can be seen that the fractional conversions are increased, most markedly at the higher flow rates; for example with $3 \mathrm{~cm}^{3} \mathrm{~min}^{-1}$, the fractional conversion has increased from 0.52 to 0.72 . This improvement is only possible if the mass transfer coefficient is higher than predicted by plug flow through the reactor and this implies that the hydrogen gas evolved at the counter electrode is, indeed, improving the mass transport regime. The increase in fractional conversion represents an increase in the rate of formation of product but at the cost is a lower current efficiency with the possibility of a loss of selectivity. Possible additional electrode reactions are $\mathrm{O}_{2}$ evolution, $\mathrm{H}_{2}$ oxidation, methanol oxidation or overoxidation of the methoxylated product. But in this particular synthesis, no over-oxidation products were observed in the GC analysis and since no $\mathrm{H}_{2}$ oxidation is found at lower charges, this is unlikely to be a major reaction.

\subsection{The Concentration of Reactant}

The obvious way to increase the rate of product formation is to increase the concentration of reactant. Hence, a series of electrolyses were carried out with concentrations of $N$-formylpyrrolidine in the range $0.1-0.75 \mathrm{M}$ and a volumetric flow rate of $1 \mathrm{~cm}^{3} \mathrm{~min}^{-1}$. Again, experiments were carried at two cell currents for each concentration (i) the cell currents predicted by equation (2) using the fractional conversion calculated from equations (1) and (5) (ii) the cell currents required for a full conversion in a single pass. The fractional conversions are reported in figure 4 . It can be seen that the fractional conversions are 
independent of the inlet concentration of $N$-formylpyrrolidine (as expected from equation (1)) and, indeed, close to those predicted by the simple model. The higher cell current, and hence higher charge input into the solution, leads to a high fractional conversion but with a lower current efficiency.

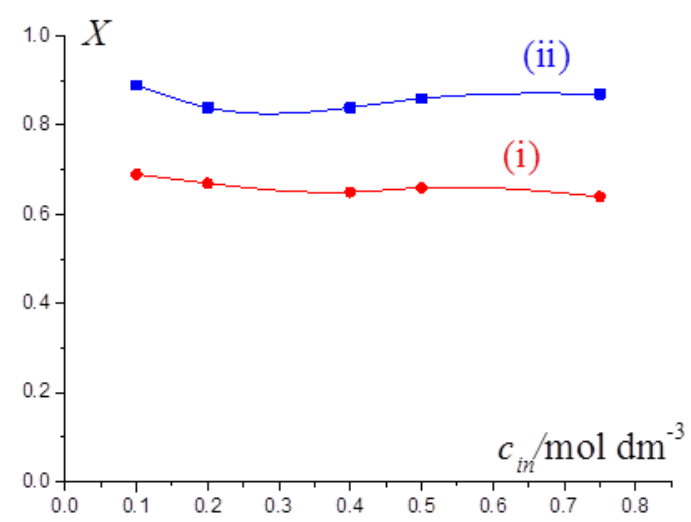

Figure 4 Fractional conversion as a function of the inlet concentration of $\mathrm{N}$ formylpyrrolidine. Electrolyses carried out with a solution volumetric flow of $1 \mathrm{~cm}^{3} \mathrm{~min}^{-1}$ and a cell current calculated (i) from equation (2) with $\mathrm{X}=0.63$. (ii) for full conversion in a single pass.

\subsection{Charge Output}

Table 2 reports the influence of the cell current (and hence the charge input into the solution) on the performance of electrolyses carried out with $0.2 \mathrm{M} \mathrm{N}$-formylpyrrolidine and a volumetric flow rate of $1 \mathrm{~cm}^{3} \mathrm{~min}^{-1}$. At the lowest cell current, the performance closely matches the theory as seen by comparison of the theoretical and experimental fractional conversions and the charge efficiency close to 1.0; the methoxylation of $\mathrm{N}$-formylpyrrolidine, (scheme 1), is the only reaction occurring at the anode. As the cell current is further increased, the fractional conversion continues to rise but the charge efficiency drops substantially. This is not a significant problem with this synthesis although this is not the general case. If further oxidation of the product at the anode is the most facile reaction, then the selectivity will decay rapidly. 
Table 2 Performance of the microflow cell as a function of the applied cell current (proportional to the charge at fixed flow rate).

\begin{tabular}{|c|c|c|c|}
\hline Cell current/A & $\begin{array}{c}\text { Fractional } \\
\text { conversion }\end{array}$ & $\begin{array}{c}\text { Product formation } \\
\text { rate/g hour }^{-1}\end{array}$ & $\begin{array}{c}\text { Fractional } \\
\text { charge efficiency }^{-1}\end{array}$ \\
\hline 0.43 & 0.67 & 1.04 & 0.98 \\
\hline 0.60 & 0.84 & 1.29 & 0.92 \\
\hline 0.80 & 0.86 & 1.33 & 0.71 \\
\hline 1.00 & 0.92 & 1.38 & 0.60 \\
\hline
\end{tabular}

Inlet solution: $0.2 \mathrm{M}$-formylpyrrolidine $+0.05 \mathrm{M} \mathrm{Bu}_{4} \mathrm{NBF}_{4}$ in methanol. Volumetric flow rate: $1 \mathrm{~cm}^{3} \mathrm{~min}^{-1}$. For comparison, the predicted conversion in this cell is 0.63 with a cell current of $0.42 \mathrm{~A}$ and the cell current needed for full conversion is $0.66 \mathrm{~A}$.

\subsection{The Rate of Product Formation}

The highest rate of product formation will occur using a high concentration of $N$ formylpyrrolidine and a high flow rate of solution provided the microflow cell continues to follow the theory and no experimental problems occur. Table 3 reports the performance of the cell in these conditions. It should be stressed that the theory now demands cell currents usually of several amperes. These are very large currents for such a small cell and also place demands on the control equipment and cell connections; indeed, the control equipment used here had a maximum output of $5 \mathrm{~A}$ and experiments at $I_{\text {cell }}>1 \mathrm{~A}$ led to rapid heating of the cell in extended experiments. The data in table 3, however, shows that electrolyses are possible and the agreement of the performance with the simple theory remains surprisingly good despite the very high rate of $\mathrm{H}_{2}$ gas evolution that leads to the solution being vigorously spat out of the cell outlet. It can be seen that the rate of product formation rises to $11.6 \mathrm{~g} \mathrm{~h}^{-1}$. Although the charge efficiency is good, the highest rates of product formation are at the expense of a slightly lower conversion. It has not been possible to achieve both a high conversion and the highest rates of product formation but this may be a result of the limitation in the cell current that could be used. 
Table 3 Performance of the microflow cell in conditions to give high rate of product formation.

\begin{tabular}{|c|c|c|c|c|c|}
\hline \multicolumn{3}{|c|}{ Experimental Conditions } & \multirow{2}{*}{$\begin{array}{l}\text { Fractional } \\
\text { conversion }\end{array}$} & \multirow{2}{*}{$\begin{array}{l}\text { Product } \\
\text { form. rate/ } \\
\mathbf{g ~ h}^{-1}\end{array}$} & \multirow{2}{*}{$\begin{array}{l}\text { Fractional } \\
\text { charge } \\
\text { efficiency }\end{array}$} \\
\hline$c_{\text {in }} / \mathrm{mol} \mathrm{dm}^{-3}$ & $Q_{V} / \mathrm{cm}^{3} \min ^{-1}$ & $I_{\text {cell }} / A$ & & & \\
\hline 0.40 & 1.0 & 0.75 (1.32) & 0.54 & 2.0 & 0.95 \\
\hline 0.40 & 1.0 & $1.25(1.32)$ & 0.82 & 2.5 & 0.89 \\
\hline 0.40 & 1.0 & $1.50(1.32)$ & 0.87 & 2.3 & 0.77 \\
\hline 0.40 & 3.0 & $2.20(4.0)$ & 0.52 & 5.2 & 0.95 \\
\hline 0.40 & 3.0 & $3.25(4.0)$ & 0.69 & 6.0 & 0.85 \\
\hline 0.75 & 1.0 & $2.5(2.5)$ & 0.87 & 4.6 & 0.87 \\
\hline 0.75 & 3.0 & $5.0(7.5)$ & 0.64 & 11.6 & 0.96 \\
\hline
\end{tabular}

Inlet solution: $N$-formylpyrrolidine $+0.05 \mathrm{M} \mathrm{Bu}_{4} \mathrm{NBF}_{4}$ in methanol. For comparison, the predicted conversion in this cell is 0.63 and 0.51 at 1 and $3 \mathrm{~cm}^{-3} \mathrm{~min}^{-1}$ respectively. The cell currents in brackets are the theoretical values for full conversion in a single pass.

\subsection{Lowering the Electrolyte Concentration}

Decreasing (or even removing) the electrolyte from the electrolysis medium can be attractive since it can greatly simplify the isolation of pure products. Inevitably, decreasing the electrolyte concentration will increase the resistance of the solution and hence the voltage drop across the interelectrode gap (with consequences in terms of demands on the control equipment and heating of the solution) and this problem will get worse with increasing cell current. Hence, there is a balance between lowering the electrolyte concentration and seeking to increase the rate of product formation. Table 4 reports a set of experiments where the electrolyte concentration has been lowered by a factor of ten to $0.005 \mathrm{M}$, the volumetric flow rate is $0.5 \mathrm{~cm}^{3} \mathrm{~min}^{-1}$. The fractional conversions remain $>0.7$ and the final experiment still corresponds to the formation of $2.0 \mathrm{~g} \mathrm{~h}^{-1}$. With this electrolyte concentration, however, the cell and control equipment would not allow a cell current above $1.0 \mathrm{~A}$.

Table 4 Fractional conversion for electrolyses with low electrolyte concentration.

\begin{tabular}{|c|c|c|}
\hline \multicolumn{2}{|c|}{ Experimental } & \multirow{2}{*}{$X$} \\
\hline $\boldsymbol{c}_{\text {in }} / \mathbf{m o l ~ d m}^{-3}$ & $\boldsymbol{I}_{\text {cell//A }}$ & \\
\hline 0.1 & 0.15 & 0.80 \\
\hline 0.4 & 0.65 & 0.71 \\
\hline 0.75 & 1.00 & 0.70 \\
\hline
\end{tabular}

Inlet solution: $N$-formylpyrrolidine $+0.005 \mathrm{M} \mathrm{Bu}_{4} \mathrm{NBF}_{4}$ in methanol. Volumetric flow rate $0.5 \mathrm{~cm}^{-3} \mathrm{~min}^{-1}$. The cell currents are the theoretical values for full conversion in a single pass. 


\section{Discussion}

Overall, it can be concluded that the simple model based on plug flow is a remarkably good model for understanding electrosynthesis in this microflow cell. Equation (1) gives a good basis for estimating the conversion that may be expected in the cell while equation (2) allows the selection of an appropriate cell current to achieve this conversion. Clearly, the gas formed at the counter electrode has little adverse effects even at high cell currents. Indeed it appears to enhance. The large volume of gas bubbles produces a more complex flow regime; slug flow occurs increasing the effective flow rate and hence the mass transfer coefficient. In addition, the bubble evolution will increase mixing between the cathode and anode, again enhancing the mass transfer coefficient. Moreover, it can be concluded that the cell performs remarkably well allowing syntheses with currents of several amperes and allowing the synthesis of several grams of product per hour with a good selectivity. This performance is, however, dependent on the methoxylation of $N$-formylpyrrolidine being a very robust reaction. The product appears not to further oxidise in a wide range of cell conditions. It must be emphasised that the cell performance would not be as good for reactions where the product has further, facile electrochemistry - using excess charge must then lead to a mixture of products.

It should also be stressed that the model also assumes that the reaction at the working electrode is mass transfer controlled. Any kinetic limitation in the reaction will inevitably lead to a lower conversion and slower product formation as well as, almost certainly, to a lower selectivity. Certainly, any attempt to select electrolysis parameters using the model will lead to inappropriate conditions.

One objective of this work was to explore how the microflow cell could be employed routinely in the synthetic laboratory. While undivided microflow electrolysis cells can carry out some valuable syntheses, their use can also be challenging, requiring an understanding of both the chemistry to be attempted and the factors that determine the performance of the electrolysis cell. Hence, what practical advice can be given to someone wishing to carry out a new synthesis?

Firstly, the chemical change expected at both working and counter electrodes should be written down and the overall chemical change examined. If a product, in addition to the desired one, is being formed at either electrode (whether formed from the reactant, solvent or electrolyte), it needs to be recognised that its concentration will build up along the channel as 
the concentration of reactant declines, possibly leading to a significant change in reaction environment. For example, setting up the cell so that acid or base is accumulating along the channel can often lead to unwanted homogeneous reactions. If such problems can be envisaged, taking steps to change the cell chemistry should be considered.

Secondly, the volumetric flow rate and the cell current need to be selected appropriately. If the mass transport characteristics of the cell are known (ie. an expression such as equation (5) is available), likely fractional conversions and appropriate cell currents can be calculated using equations (1) and (2). If such background information is not available, two approaches to setting the cell current are possible. In each case starting with a modest volumetric flow rate (i) calculate the cell current required for a full conversion in a single pass using equation (2) with $X=1$ and start with this current. (ii) guess a value for the mass transfer coefficient and again use equations (1) and (2) to estimate an appropriate cell current - with a narrow channel and flow rates of a fraction of $1 \mathrm{~cm}^{3} \mathrm{~min}^{-1}$, a value of $k_{m}=$ $10^{-3} \mathrm{~cm} \mathrm{~s}^{-1}$ is likely to lead to a reasonable estimate of the cell current. If cell currents selected in this way do not give the desired conversions and rate of product formation, the cell current can be increased but this will inevitably lead to low charge efficiency with the likelihood of byproducts being formed.

\section{Experimemtal}

The electrolysis cell used in this work, see figure 1, has been described previously [3] and was fabricated by Syrris Ltd. It is a unit only $10 \mathrm{~cm} \mathrm{x} 7 \mathrm{~cm} \mathrm{x} 4 \mathrm{~cm}$. The cell has a carbon filled polyvinylidene fluoride anode and steel cathode plates. It has a single, convoluted channel with pathlength $70 \mathrm{~cm}$, width $0.15 \mathrm{~cm}$ and interelectrode gap $0.02 \mathrm{~cm}$ formed by a patterned FFKM perfluoroelastomer gasket held in place by a groove machined into the steel cathode. This gives a total electrode area of $10.5 \mathrm{~cm}^{2}$ and a channel volume of $0.21 \mathrm{~cm}^{3}$ [3].

The microflow circuit, the chemicals and gas chromatographic (GC) analysis of $\mathrm{N}$ formylpyrrolidine and methoxylated product have all been described previously [16-17]. The performance was estimated from both the consumption of reactant and the formation of product and, in general, the selectivity is close to 1.0. Unless otherwise stated, all electrolysis were carried out at room temperature with $5.0 \mathrm{~cm}^{3}$ of methanol containing $0.05 \mathrm{M} \mathrm{Bu}_{4} \mathrm{NBF}_{4}$ + the stated concentration of $N$-formylpyrrolidine. 


\section{Acknowledgements}

The Authors would like to acknowledge the financial support from EPSRC contract number EP/L003325/1, Astrazeneca, GlaxoSmithKline and the A-I Chem Channel project which was selected by the European INTERREG IV A France (Channel) - England Cross-border cooperation Programme, co-financed by ERDF.

\section{References}

1. a) Watts, P.; Haswell, S. J. Chem. Soc. Rev. 2005, 34, 235-246. b) Mason, B.P.; Price, K.E.; Steinbacher, J.L.; Bogdan, A.R.; McQuade, D.T. Chem. Rev. 2007, 107, 23002318. c) Fukuyama, T.; Rahman, T.; Sato M.; Ryu, I. Synlett. 2008, 151-163. d) Yoshida, J. Flash Chemistry: Fast Organic Synthesis in Microsystems, Wiley-VCH: Weinheim, 2008. e) Chemical Reactions and Processes under Flow Conditions, Eds. Luis S.V.; Garcia-Verdugo, E. Royal Society of Chemistry, 2009. f) Microreactors in Organic Synthesis and Catalysis, $2^{\text {nd }}$ Edn.; Eds., Wirth, T., Wiley-VCH: Weinheim, 2013. g) Microreactors in Preparative Chemistry, Eds., Reschetilowski, W., Wiley-VCH: Weinheim, 2013. h) Watts, K.; Baker A.; Wirth, T. J. Flow Chem., 2014, 4, 2-11.

2. a) Yoshida. J. Chem. Commun. 2005, 4509-4516. b) Horii, D.; Atobe, M.; Fuchigami T.; Marken, F. J. Electrochem. Soc. 2006, 156, D143-D147. c) Saito, K.; Ueoka, K.; Matsumoto, K.; Suga, S.; Nokami T.; Yoshida, J. Angew. Chem Int. Ed. 2011, 50, $5153-$ 5156. d) Attour, A.; Dirrenberger, P.; Rode, S.; Ziogas, A.; Matlosz M.; Lapique, F. Chem. Eng. Sci. 2011, 66, 480-489. e) Kupper, M., Hessel, V.; Lowe, H.; Stark, W.; Kinkel, J.; Michel, M.; Schmidt-Traub, H. Electrochim. Acta. 2003, 48, 2889-2896. f) Simms, R.; Dubinsky, S.; Yudin, A.; Kumasheva, E. Lab. Chip. 2009, 9, 2395-2397. g) Ziogas, A.; Kolb, G.; O’Connell, M.; Attour, A.; Lapicque, F.; Matlosz M.; Rode, S. J. Appl. Electrochem. 2009, 39, 2297-2313. h) Bouzek, K.; Jiřičný, V.; Kodým, R.; Křišstál, J.; Bystroň, T. Electrochim. Acta. 2010, 55, 8172-8181. i) Kashiwagi, T.; Amemiya, F.; Fuchigami, T.; Atobe, M.; Chem. Commun. 2012, 48, 2806-2808. j) Kuleshova, J.; HillCousins, J. T.; Birkin, P. R.; Brown, R. C. D.; Pletcher, D.; Underwood, T.J. Electrochim. Acta. 2011, 56, 4322-4326.

3. Kuleshova, J.; Hill-Cousins, J. T.; Birkin, P. R.; Brown, R. C. D.; Pletcher, D.; Underwood, T.J. Electrochim. Acta. 2012, 69, 197-202. 
4. Roth, G. P.; Stalder, R.; Long, T. R.; Sauer D.R.; Djuric. S. W.; J. Flow Chem. 2013, 3, $34-40$.

5. Stalder, R.; Roth, G. P. Med. Chem. Lett. 2013, 4, 1119-1123.

6. Steckhan, E.; Arns, T.; Heineman, W. R.; Hilt, G.; Hoormann, D.; Jörissen, J.; Kröner, L.; Lewall, B.; Pütter. H. Chemosphere. 2001, 43, 63-73.

7. Paddon, C.A.; Atobe, M.; Fuchigami, T.; He, P.; Watts, P.; Haswell, S. J.; Pritchard, G. T.; Bull S. D.; Marken, F. J. Appl. Electrochem. 2006, 36, 617-634.

8. a) Bard A. J.; Faulkner, L. R. Electrochemical Methods - Fundamentals and Applications. John Wiley. 2001. b) Walsh, F. C. A First Course in Electrochemical Engineering. The Electrochemistry Consultancy. 1993. c) Pletcher D.; Walsh, F.C. Industrial Electrochemistry. $2^{\text {nd }}$ Edn. Chapman and Hall, London, 1990.

9. Scialdone, O.; Guarisco, C.; Galia, A. Electrochim. Acta. 2011, 58, 463-373. 